\title{
DIEZ AÑOS DE MERCK: \\ UNA DÉCADA DE EVOLUCIÓN DEL ARBITRAJE COMERCIAL INTERNACIONAL EN COLOMBIA
}

\author{
Eduardo Zuleta Jaramillo \\ Alberto Zuleta Londoño
}

\section{Introducción}

Hace una década la Corte Suprema de Justicia de Colombia resolvió negativamente una solicitud de exequátur presentada por los apoderados de tres sociedades extranjeras: (i) Merck y Co Inc.; (ii) Merck Frosst Canada Inc; y (iii) Frosst Laboratories Inc. El objeto de la solicitud de exequátur era un "Laudo Interlocutorio Respecto de la Jurisdicción del Tribunal de Arbitramento", dictado por un tribunal de arbitramento internacional administrado por la Cámara de Comercio Internacional ("CCI") y cuya sede era la ciudad de Newark, estado de Nueva Jersey, Estados Unidos de América. Las partes demandantes en el arbitraje que dio origen al laudo eran las tres sociedades mencionadas (a las que nos referiremos colectivamente como las "Compañías Merck") y la demandada una sociedad colombiana, Tecnoquímicas S.A. ("Tecnoquímicas"). Esa decisión de la Corte Suprema y las controversias jurídicas que la rodearon moldearon gran parte de las instituciones jurídicas que sirven de fundamento para el arbitraje comercial internacional en Colombia. Muchos de sus efectos continúan vigentes hoy.

El presente artículo examina en detalle las decisiones que se adoptaron en Colombia y el exterior a raíz del la controversia entre las Compañías Merck y Tecnoquímicas (en adelante, globalmente considerado, el "Caso Merck"). En primer lugar se 
describirá el caso, así como cada una de las decisiones en torno al mismo. En segundo lugar, se hará un análisis del marco jurídico que sirvió a las distintas autoridades colombianas para resolver el Caso Merck. En tercer lugar, se analizará la evolución del arbitraje internacional colombiano desde Merck hasta hoy. Finalmente, se expondrán las conclusiones del caso.

\section{El Caso Merck}

En 1986 las Compañías Merck celebraron cinco contratos diferentes con Tecnoquímicas (en adelante los "Contratos"), para la licencia, fabricación y distribución de ciertos productos por parte de esta última compañía. Cada uno de los Contratos contenía una cláusula arbitral (en adelante las "Cláusulas Arbitrales") en la que se preveía un tribunal de arbitramento que sesionaría en la ciudad de Newark, estado de Nueva Jersey, Estados Unidos de América, al amparo de las reglas de la CCI y

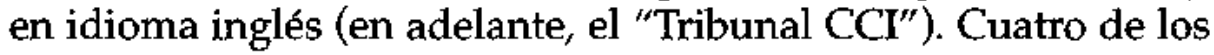
Contratos se regirían, según su mismo texto, por la ley del estado de Nueva Jersey, y el restante por la ley colombiana.

Antes de la expiración del plazo contractual las Compañías Merck notificaron a Tecnoquímicas su intención de no prorrogar los Contratos. Tecnoquímicas manifestó, a su vez, que retendría dineros debidos a las Compañías Merck, amparada en la autorización que la ley colombiana extiende en esa materia a los agentes mercantiles.

\subsection{La convocatoria de un tribunal de arbitramento en Colombia y la actuación del Centro de arbitraje y Conciliación de la Cámara de Comercio de Bogotá}

Al vencimiento del término de los Contratos, Tecnoquímicas, invocando su calidad de agente comercial, retuvo sumas de dinero correspondientes a pago que debía entregar 
a Merck bajo los Contratos. Las Compañías Merck presentaron entonces una solicitud de arbitraje ante la Corte Internacional de Arbitraje de la Cámara de Comercio Internacional, entidad administradora prevista en las Cláusulas Arbitrales. Por su parte, Tecnoquímicas presentó ante el Centro de Arbitraje y Conciliación de la Cámara de Comercio de Bogotá una demanda arbitral para que se declarara la existencia de un contrato de agencia comercial y se pagaran las sumas correspondientes a la terminación de ese tipo de contratos.

El razonamiento de Tecnoquímicas para presentar la solicitud de arbitraje ante el Centro de Arbitraje y Conciliación de la Cámara de Comercio de Bogotá puede resumirse así: Los Contratos conformaban una sola relación de agencia mercantil y en virtud del artículo 1328 del Código de Comercio, norma que Tecnoquímicas consideró de estricto orden público, "los contratos de agencia comercial que se ejecuten en el territorio nacional quedan sujetos a las leyes colombianas". La citada sujeción a las normas colombianas se refiere no solamente a las disposiciones legales sustantivas que regulan el contrato de agencia, sino también a las normas procesales nacionales y a la competencia para resolver conflictos relativos a contratos que se dicen de agencia y que hayan sido ejecutados en Colombia. En consecuencia los conflictos relativos a agencias comerciales ejecutadas en Colombia solamente podían ser resueltos por jueces colombianos, en Colombia, en idioma castellano y con sujeción a las reglas del Código de Procedimiento Civil. Las convenciones ratificadas por Colombia en materia de arbitraje condicionan la validez de la cláusula arbitral a que la misma no viole el orden público colombiano y a que el laudo que resulte se pueda ejecutar en Colombia.

Esta línea de argumentación tendría que haber conducido a que el litigio se sometiera por parte de Tecnoquímicas a un juez ordinario en Colombia. Sin embargo, apoyada en la divisibilidad de la cláusula arbitral, consideró que todas las estipulaciones relativas al lugar e idioma del arbitraje, forma de nombramiento 
de los árbitros y reglas de procedimiento eran ineficaces por controvertir normas colombianas de orden público, pero que debía preservarse la parte sustancial de la cláusula, es decir, la intención de someter los conflictos a arbitraje. Concluyó entonces que, habiéndose pactado arbitraje, y siendo únicamente eficaz la intención de arbitrar pero no el foro ni las reglas elegidas en las cláusulas compromisorias, la competencia para resolver el conflicto le correspondía al Centro de Arbitraje y Conciliación de la Cámara de Comercio de Bogotá.

El mencionado Centro admitió la convocatoria, la notificó a las Compañías Merck e indicó que procedería al nombramiento del tribunal.

Las Compañías Merck presentaron recurso de reposición solicitando que se rechazara la convocatoria arbitral, en la medida en que el Centro de Arbitraje y Conciliación de la Cámara de Comercio de Bogotá no había sido designado por las partes como el centro encargado de administrar el arbitraje.

El Centro de Arbitraje y Conciliación de la Cámara de Comercio de Bogotá decidió declararse inhibido para resolver los recursos citados. Al respecto, y siguiendo la que había sido su postura tradicional, el citado Centro argumentó que -en su criterio- no contaba con atribución jurisdiccional alguna para definir de manera definitiva asuntos procesales y sustanciales de fondo planteados por las partes en la etapa prearbitral (como es el caso de la competencia para conocer de la convocatoria arbitral), toda vez que esa es una atribución propia y un asunto que únicamente le corresponde resolver a los árbitros. Como consecuencia de esa decisión continuó con el trámite prearbitral y finalmente designó árbitros 1 .

1. En ese entonces existía un debate sobre si las instituciones administradoras de arbitraje tenian o no una función jurisdiccional. Tema que fue finalmente cerrado con la sentencia de la Corte Constitucional que declaró inexequible el trámite prearbitral tramitado por los Centros de Arbitraje. Cabe anotar que el Centro de Arbitraje y Conciliación de la Cámara de Comercio de Bogotá envió una nota a la Corte Intemacional de Arbitraje de la CCI solicitando que como "entidad nominadora" procediera a nombrar los árbitros y señalando que si no lo hacia lo haría el Centro. La carta la res- 


\subsection{La actuación del tribunal de arbitramento designado por el Centro de Arbitraje y Conciliación de la Cámara de Comercio de Bogotá}

En la primera audiencia de trámite el tribunal así designado (el "Tribunal de Arbitraje Colombiano") se declaró competente para conocer del caso con los siguientes argumentos:

- Los contratos se ejecutaron en territorio colombiano.

- La convocante alega que los contratos configuran una relación de agencia comercial.

- La competencia del tribunal arbitral se determina precisando el objeto sobre el cual versa el litigio pues "la doctrina explica que el factor objetivo de la competencia atiende la naturaleza del asunto, siendo el legislador quien asigna una determinada competencia, en consideración la índole de la relación jurídica que se debate, y por ello el juez debe asumirla sin consideración a que realmente exista esa relación jurídica" ${ }^{2}$

- Como el objeto sobre el cual versa el litigio es la existencia de una agencia comercial, debe darse aplicación al artículo 1328 del Código de Comercio en virtud del cual "Para todos los efectos, los contrato de agencia comercial que se ejecuten en territorio nacional quedan sujetos a las leyes colombianas. Cualquier estipulación en contrario se tendrá por no escrita".

- La mencionada disposición, al utilizar la expresión "para todos los efectos", se refiere tanto a la ley sustancial como a la ley procesal.

- El artículo 1328 del Código de Comercio es de orden público y por ende no admite pacto en contrario. La sanción prevista por la norma en caso de transgresión es la ineficacia del pacto, ineficacia que no requiere declaración judicial.

pondió el entonces consejero Fernando Mantilla Serrano diciendo que la CCI no era "nominadora" sino la administradora y que cualquier nombramiento que hiciera el Centro sería ilegal. El Centro, argumentando que la CCI no había nombrado dentro del plazo, procedió al nombramiento.

2. Arbitramento de Tecnoquímicas S.A. vs. Frosst Laboratories y otros, Acta No. 3, marzo I9 de 1999. 
- La ineficacia, sin embargo, es parcial, solamente se refiere al foro pactado para el arbitraje, al idioma, a la forma de nombramiento de los árbitros y a las reglas de procedimiento, por cuanto al admitir esta ineficacia parcial "se destruyen, al menos parcialmente, los efectos de la cláusula y se concluirá que en casos como el sub lite no es admisible el arbitraje internacional. Si se entiende que la cláusula es íntegramente ineficaz, también se darán los efectos anteriores pero simultáneamente se impedirá el acceso al arbitraje nacional, de lo cual resultaría que el conflicto deberán conocerlo los jueces locales, interpretación que estaría frustrando el verdadero querer de las partes, que concretamente fue excluir estos conflictos de la justicia ordinaria" ${ }^{3}$

Interpuesto el correspondiente recurso de reposición frente a la decisión de competencia, el Tribunal de Arbitraje Colombiano insistió en declararse competente. Para el efecto, reiteró los argumentos inicialmente expuestos y trajo a colación los siguientes ${ }^{4}$ :

3. Arbitramento de Tecnoquímicas S.A. vs. Frosst Laboratories y otros, Acta No. 3, marzo 19 de 1999. Sobre este particular, en concepto allegado al proceso, el Dr. Allvaro Mendoza Ramírez, citado por los árbitros como una de las fuentes de su decisión manifestó "En forma alguna en mi criterio, puede traerse a cuento el proveído anterior para pretender que si la voluntad de las partes apuntó hacia un arbitramento de carácter internacional y hacia un centro arbitral diferente, esta voluntad pueda preservarse en un aspecto mínimo del compromiso, pero sustrayendo dicho aspecto de la clase de arbjtramento y del centro encargado de adelantarlo. Es claro que los casos difieren sensiblemente (...)"El raciocinio expresado en el acta no. 2 lleva a una labor de poda de la voluntad contractualmente expresada, de tal naturaleza que la desfigura completamente. No se trata aquí, como ocurrió en el laudo en el cual el suscrito participó, de entender que puede hacerse una diferencia entre el propósito de comprometer y la forma de designar los árbitros, sino que se afecta la misma intención compromisoria, al deslindarla de la clase de arbitramento y del centro arbitral escogido por las partes. Este sistema de eliminar lo sustancial de una estipulación para preservar únicamente una parte tan pequeña de ella, que dificilmente puede suponerse como propia de la voluntad realmente expresada en el contrato, desfigura totalmente dicha voluntad"..."En mi criterio, si se quiere desconocer, no solamente el sistema previsto para la designación de átbitros, sino la misma condición y clase de arbitramento escogido (un arbitramento de carácter internacional), así como el centro de arbitraje expresamente pactado, se está reservando un aspecto muy pequeño de la voluntad compromisoria, y todo lo anterior para afirmar que el tribunal convocado es competente. Es algo así como aferrarse a un clavo ardiente, único soporte para la competencia de los árbitros, cuando ellos mismos deciden eliminar supuestos que deben tenerse como fundamentales en la mencionada voluntad compromisoria (...)".

4. Arbitramento de Tecnoquimicas S.A. vs. Frosst Laboratories y otros, Acta No. 4, abril 8 de 1999. 
- La competencia del tribunal arbitral se determina por la pretensión de la convocante.

- No es la cláusula compromisoria la que define la competencia de los árbitros.

- Ninguno de los tratados internacionales ratificados por Colombia en materia de arbitraje autoriza a pactar contra el artículo 1328 del Código de Comercio; la ley 315 de 1996 (ley de arbitraje internacional) sí lo autoriza, pero no es aplicable al caso por ser posterior a la fecha del pacto arbitral.

- Los tratados internacionales sobre arbitraje siempre dejaron a salvo las normas de orden público al paso que la Ley 315 de 1996 permite pactar aún contra las normas de orden público.

- El artículo 1328 del Código de Comercio es norma de orden público internacional o absoluto y por ello, aunque Colombia haya suscrito a la Convención de Nueva York, "tal convención no modificó ni derogó el artículo 1328 del Código de Comercio, ni prevalece sobre tal norma" 5 .

Dejando de lado la discutible tesis de que la jurisdicción del tribunal arbitral no se funda en el pacto arbitral sino en las pretensiones de la demanda, la posición asumida por el Tribunal Arbitral Colombiano generaba una paradoja consistente en la posibilidad de que el tribunal acudiera a la supuesta ineficacia parcial de la cláusula fundándola en las normas de agencia mercantil previstas en la ley colombiana, y al momento de fallar encontrara que tal agencia mercantil jamás existió. Sin embargo, el tribunal insistió en su competencia.

5. Arbitramento de Tecnoquimicas S.A. vs. Frosst Laboratories y otros, Acta No. 4, abril 8 de 1999. 


\subsection{La acción de tutela: el trámite de la primera instancia}

Las Compañías Merck presentaron ante la sala civil del Tribunal Superior de Distrito Judicial de Bogotá una acción de tutela (equivalente al amparo en otros países de la región) contra el Centro de Arbitraje y Conciliación de la Cámara de Comercio de Bogotá, por vulneración de los derechos constitucionales fundamentales al debido proceso, a la defensa y a la igualdad.

Se argumentó que las normas vigentes al momento de instaurarse la demanda arbitral por Tecnoquímicas otorgaban al director del Centro las facultades necesarias para resolver sobre la admisión, inadmisión o rechazo de la solicitud de convocatoria a un trámite arbitral, así como sobre los recursos que se presenten contra sus decisiones, no pudiendo entonces declararse inhibido para asumir tales obligaciones.

$\mathrm{Al}$ evitar pronunciarse de fondo sobre el recurso interpuesto contra la admisión, el director del Centro generó, entre otras, las siguientes consecuencias:

- La existencia de dos trámites arbitrales, entre las mismas partes y por los mismos hechos, en dos lugares diferentes: Bogotá y Newark, Nueva Jersey.

- La necesidad de adelantar un trámite arbitral en Bogotá, que es absolutamente nulo por falta de jurisdicción y competencia y que debió ser rechazado por el Centro de Arbitraje, mediante una simple revisión prima facie del pacto arbitral.

- La necesidad de tener que integrar un tribunal de arbitramento, para que se declare la falta de jurisdicción - no su propia competencia- lo cual ha debido ser resuelta en el auto admisorio de la demanda. 
- La obligación de cancelar los honorarios de árbitros nombrados por una institución diferente a la pactada por las partes so pena de que, a la luz de la ley Colombiana, que el director del Centro consideró aplicable, se declaren extinguidos los efectos de un pacto arbitral.

Las Compañías Merck consideraron que se había violado su derecho de defensa y el debido proceso, a través de lo que se conoce jurisprudencialmente como la "vía de hecho"; esto es para el caso concreto, una actuación adelantada por una autoridad y consignada en una decisión en particular, caracterizada por una arbitrariedad, subjetividad, parcialidad y voluntarismo desconocedor de los principios mínimos, objetivos y razonables de legalidad que deben gobernar el caso en concreto.

En cuanto a la violación del derecho a la igualdad se alegó que el Centro había proferido el 13 de mayo de 1998, dentro de tres trámites arbitrales contra una misma empresa, decisiones por medio de las cuales se ordenó revocar providencias dictadas anteriormente; esto es, los autos por medio de los cuales el Centro admitió cada una de las solicitudes de convocatoria del tribunal de arbitramento. Dicho en otras palabras: dentro de los trámites arbitrales contra una empresa el Centro Arbitral sí tuvo competencia para admitir o para inadmitir (que es lo mismo que revocar el auto de admisión), pero en el trámite arbitral adelantado contra las Compañías Merck, resultó que ese mismo Centro se declaró inhibido para conocer y resolver un recurso de reposición contra el auto que admitió la convocatoria al tribunal arbitral.

Por último se advirtió que la acción de tutela no pretendía en momento alguno cuestionar el asunto de fondo en cuanto al pacto arbitral, es decir, lo que se debatía en el proceso. Por ese motivo, se recalcó con insistencia que no se estaba solicitando que mediante una sentencia de tutela se obligara al Centro de Arbitraje y Conciliación de la Cámara de Comercio de Bogotá a adoptar una posición favorable a los argumentos jurídicos presentados por las Compañías Merck: Io que se solicitó fue un pro- 
nunciamiento que resolviera los recursos de acuerdo con la competencia legal de que estaba investida el mencionado Centro.

Mediante decisión del 24 de agosto de 1998 la sala civil del Tribunal Superior del Distrito Judicial de Bogotá, decidió -por mayoría - conceder la acción de tutela interpuesta por las Compañías Merck. Por considerar que el director del Centro había incurrido en una conducta violatoria del derecho al debido proceso que constituye una vía de hecho por "desconocimiento grave y flagrante de la normativa que rige el proceso arbitral en el punto abordado, evento en el cual la autonomía e independencia del funcionario no prevalece, al haber antepuesto su voluntad o capricho al mandato de la ley, al sustraerse a la obligación de documentar en una providencia las razones lógico-jurídicas tendientes a desatar el recurso formulado dentro de la actuación que se surte bajo su dirección".

En virtud de lo anterior, el Tribunal Superior consideró que la acción de tutela interpuesta debía prosperar con el objeto único de que el Centro profiriera una decisión de mérito sobre el recurso de reposición presentado por las Compañías Merck, teniendo el Centro autonomía e independencia para adoptar la decisión sobre el particular.

En cumplimiento de lo dispuesto por el Tribunal Superior de Bogotá el Centro profirió un auto de fecha 28 de agosto de 1998 en el que, después de algunas consideraciones, concluyó que la de la simple lectura de la cláusula arbitral pactada por las partes "se observa que las partes acordaron que todos los conflictos serian resueltos bajo las reglas de conciliación y arbitramento de la Cámara de Comercio Internacional, y en aplicación de dichas reglas, el centro acordado es la Cámara de Comercio Internacional". Como consecuencia de lo anterior, el Centro tomó la decisión de revocar la convocatoria arbitral presentada por Tecnoquímicas contra las Compañías Merck. 
Diez años de Merck: una década de evolución del Arbitraje comercial internacional en Colombia

\subsection{La acción de tutela: el trámite de la segunda instancia}

Tanto el Centro como Tecnoquímicas decidieron impugnar la decisión de tutela adoptada por la sala civil del Tribunal Superior de Bogotá.

El Centro fundó su impugnación en el hecho de que su director no es un juez, no cuenta con funciones jurisdiccionales y sus actos tampoco pueden revestir tal carácter. Según el Centro las actividades que se adelantan durante la etapa prearbitral no comportan actividad jurisdiccional, sino que se trata de una colaboración de carácter instrumental que el Centro le presta a quienes acuden al proceso arbitral. El Centro no admite una demanda arbitral propiamente dicha, sino tan sólo la convocatoria a arbitrar, pues las decisiones en torno a la demanda, la contestación, las excepciones y la reconvención, son asuntos que competen únicamente a los tribunales arbitrales. De acuerdo con estas consideraciones, para el Centro la decisión de haberse abstenido de resolver los recursos interpuestos por las Compañías Merck y haber deferido cualquier decisión sobre el particular al tribunal de arbitramento, no fue un acto de carácter jurisdiccional $y$, en todo caso, fue un acto ajustado a derecho.

Tecnoquímicas apoyó la tesis del Centro y argumentó que las Compañías Merck contaban con otro mecanismo de defensa judicial, como era el caso de las excepciones previas, lo que hacía que la acción de tutela no prosperara, máxime cuando-en su criterio- la acción de tutela no se había interpuesto como mecanismo transitorio para evitar un perjuicio irremediable.

Por su parte, las Compañías Merck presentaron sus argumentos por los cuales estimaban que la sentencia de primera instancia debía ser confirmada por parte de la Sala Civil y Agraria de la Corte Suprema de Justicia. Además de reiterar las razones expuestas en la demanda de tutela, señalaron las interesadas que, aun aceptando en gracia de discusión que el Centro no admite una demanda sino una solicitud de convocar un arbitra- 
je, lo cierto es que sobre esa decisión de admitir o no la convocatoria procede el recurso de reposición y, por lo mismo, el Centro y sólo el Centro era el responsable de resolverlo.

La Sala de Casación Civil y Agraria de la Corte Suprema de Justicia, a través de la sentencia del 25 de septiembre de 1998, resolvió revocar la sentencia proferida en la primera instancia y, en su lugar, rechazar la acción de tutela interpuesta por las Compañías Merck.

La Corte Suprema estimó que la discusión entre las partes que participan en el proceso de tutela "encierra como aspecto básico y distinto por entero de la cuestión de misma, un problema hemenéutico, una diferencia de criterios que se apoyan, cada uno, en una ilación esquemática y logica que, de entrada, excluye la arbitrariedad, insita en toda via de hecho, como de manera unanime y uniforme se ha afirmado en la jurisprudencia constitucional (...)". Por esta razón, consideró la Corte que la decisión del director del Centro "no fue una denegación de respuesta, no constituyó una vía de hecho o una violación del debido proceso, por cuanto el fundamento de la mal llamada inhibición radicó precisamente en no poder entrar de fondo en el asunto, sin usurpar la competencia del tribunal, para lo cual se basó en una interpretación normativa y racional (...)".

La Corte no se pronunció a favor de alguna de las tesis que han sido materia de debate, ni consideró que los directores de los centros de arbitraje ejercen funciones jurisdiccionales; tampoco avaló la tesis de que son meros administradores que cumplen funciones secretariales. Optó por considerar que se trataba simplemente de un caso en que existían diferencias de interpretación jurídica y que, por lo tanto, no procedía la tutela. 


\subsection{La competencia del Tribunal CCI y la solicitud de exequátur de la decisión que la estableció}

Mientras se tramitaba la tutela en la segunda instancia, se inició ante la sala civil de la Corte Suprema de Justicia un proceso de exequátur, con el fin de que se reconociera en Colombia la decisión sobre jurisdicción adoptada por el Tribunal CCI.

En Merck et al v. Tecnoquímicas ${ }^{6}$, la Corte Suprema de Justicia de Colombia negó el reconocimiento de la decisión proferida por el Tribunal CCI en la que el árbitro -quien denominó su decisión "Laudo Interino sobre Jurisdicción" ${ }^{\prime 7}$ - resolvió lo siguiente: (i) que los pactos arbitrales convenidos por las partes eran válidos; (ii) que el árbitro único designado por la Corte Internacional de Arbitraje de la CCI tenía jurisdicción para resolver las controversias que le habían sido sometidas; (iii) que la demandada debía abstenerse de continuar acciones en contra de los pactos arbitrales, incluida la acción iniciada ante el Centro de Arbitraje y Conciliación de la Cámara de Comercio de Bogotá; y (iv) que el tribunal se abstendría de decidir, por el momento, sobre los reclamos por daños presentados por las Compañías Merck, los cuales serían decididos en el laudo final.

En la decisión inicial ${ }^{8}$, la Corte Suprema de Justicia consideró lo siguiente:

(i) El reconocimiento y ejecución de laudos extranjeros está sujeto a las normas del Código de Procedimiento Civil. Dichas normas remiten a los tratados internacionales y, en ausencia de los mismos, a la reciprocidad. Como

6. Decisiones de enero 26 y marzo 1 de 1999. Yearbook Commercial Artitration, Vol XXVI-2001, The Hague, 2001, Kluwer Law, pags. 755-766. Véase también en relación con este mismo caso, Zuleta, Eduardo "Special constiucional Action to Preserve International Arbitration " en Jotirnal of International Arbitration, Vol. 8., No. 4, Agosto 2001, The Hague, 2001, Kluwer Law International, pp. 475 a 480 .

7. Interim Award on Jurisdiction en el original; traducción del autor.

8. Corte Suprema de Justicia, Sala de casación Civil y Agrária. Decisión del veintiséis (26) de enero de mil novecientos noventa y nueve (1999); expediente No. 7474. Magistrado, Dr. Pedro Lafont Pianetta 
existe un tratado internacional -La Convención de Nueva York de 1958- procede entonces aplicarla. Acudiendo al artículo 695 del Código de Procedimiento Civil, el cual versa sobre los requisitos de la demanda y remite parcialmente a las causales de denegación del exequatur previstas en el artículo 694, sostuvo que la misma no podía versar sobre derechos reales constituidos sobre bienes ubicados en Colombia; no se podía oponer a leyes $\mathbf{u}$ otras disposiciones de orden público; $y$ no podía referirse a asuntos que sean de competencia exclusiva de los jueces colombianos.

(ii) La determinación de la naturaleza de las providencias cuyo reconocimiento es posible debe establecerse, en primer lugar, acudiendo a los tratados internacionales $y$, en segundo lugar, a la ley colombiana ${ }^{9}$.

(iii) Dado que la Convención de Nueva York no define lo que se entiende por sentencia arbitral, debe acudirse, en primer lugar, al espíritu de dicho instrumento internacional y, en segundo lugar, a la ley colombiana.

(iv) El alcance que resulta más ajustado al espíritu del tratado y a la ley colombiana es el de concebir la "sentencia arbitral" como aquella que pone fin al proceso arbitral, definiendo las diferencias sometidas a consideración del tribunal arbitral.

(v) La decisión sobre jurisdicción es, independientemente de su denominación, una decisión simplemente previa y preparatoria.

(vi) La anterior interpretación coincide con el alcance que la expresión "sentencia arbitral" tiene a la luz de la ley colombiana.

9. Para legar a esta conclusión la Corte invocó el artículo 25 , numeral 4 del código de procedimiento civil y el artículo 693 (incisos $1^{\circ}$ y $2^{\circ}$ del misno código). 
Diez años de Merck: una décade de evolución del Arbitraje comercial intemacional en Colombia

(vii) Bajo la ley colombiana, la decisión sobre la competencia del tribunal de arbitramento es un auto y no una sentencia.

(viii) No puede concederse el exequátur sobre una decisión que es susceptible de ser modificada posteriormente por el tribunal de arbitramento.

(ix) Conceder el exequátur en el presente caso implicaría definir un conflicto de competencias entre un tribunal de arbitramento extranjero (el que profirió el laudo) y la jurisdicción colombiana (al tribunal arbitral designado por el Centro), lo cual desbordaría el marco legal del ordenamiento jurídico colombiano, pues la decisión que resuelve este conflicto debe ser la que al respecto tome el juez colombiano, dentro del proceso que se adelante en Colombia y no la que tome la Corte Suprema de Justicia. Esto se debe al carácter de orden público y el principio general de territorialidad de las normas procesales.

La anterior decisión fue objeto de un recurso de súplica, el cual fue resuelto el primero de marzo del mismo año ${ }^{10}$. En este caso, el recurrente señaló que el concepto de "sentencia arbitral" debía establecerse a la luz del derecho de la sede del arbitraje, pues es la ley que resulta aplicable en subsidio de las reglas escogidas por las partes, según se desprende de una interpretación armónica de la ley 315 de 1996 (ley de arbitraje internacional) y la ley 39 de 1990 (por la cual se aprobó la Convención de Nueva York). La Corte Suprema de Justicia insistió en que es el Código de Procedimiento Civil el que debe aplicarse para determinar cuál es la ley aplicable para establecer el concepto de "sentencia arbitral", y que este código ordena que sean los tratados internacionales $y$, en subsidio, la ley colombiana. La Corte repitió, entonces, el análisis que había hecho en el fallo anterior, y con-

10. Corte Suprema de Justicia, Sala de casación Civil y Agraria. Decisión del primero $\left(1^{4}\right)$ de marzo de mil novecientos noventa y nueve (I999). Expediente E-7474. Magistrado ponente, Dr. José Fernando Ramírez Gómez. 
cluyó que solamente los laudos definitivos pueden entenderse como "sentencias arbitrales" para efectos de ser reconocidos por medio de un proceso de exequátur.

\subsection{La selección y la revisión de la acción de tutela por parte de la Corte Constitucional}

Las Compañías Merck solicitaron a la Corte Constitucional seleccionar la acción de tutela, por tratarse de un asunto sobre el que no existía antecedente jurisprudencial alguno. En el respectivo escrito se argumentó que la Corte Suprema no tuvo en cuenta que la actuación cuestionada por parte del director del Centro constituía una vía de hecho vulneradora de los derechos constitucionales al debido proceso y a la igualdad $-\mathrm{y}$, por lo mismo, objeto de protección a través de la acción de tutela- independientemente de la posición jurídica que se adoptare. En la medida en que el presente asunto trataba de la decisión del director del Centro de declararse inhibido de conocer de un recurso de reposición presentado contra un acto que el mismo director había expedido, la discusión acerca de si el referido funcionario actuaba bajo unos postulados jurídicos o bajo otros tenía como único fin el explicar que en todos los eventos posibles la decisión inhibitoria dictada fue flagrantemente violatoria del ordenamiento jurídico y constituye un acto jurídico caprichoso, arbitrario y desconocedor de la ley que bien valía la pena ser cuestionado y revocado a través de la acción de tutela. En efecto, si el Centro decidió admitir la demanda o la convocatoria al tribunal y posteriormente optó porque no podía conocer de los recursos presentados contra su propia providencia, bajo el argumento de que se trataba de un asunto de competencia y jurisdicción que la ley le había conferido definir a los árbitros, entonces, ese funcionario no debió haber dictado la providencia admisoria del arbitramento en una primera instancia.

El Centro y Tecnoquímicas presentaron sus respectivas consideraciones y solicitudes ante la Corte Constitucional, básica- 
mente exponiendo la misma posición jurídica que se sometió ante la primera y la segunda instancia.

La Corte Constitucional resolvió seleccionar para su revisión la acción de tutela interpuesta por las Compañías Merck. Como consecuencia de la trascendencia del asunto, no fue la mencionada sala la encargada de resolverlo, sino que la acción de tutela pasó a consideración de la sala plena de la Corte.

En su sesión del 18 de agosto de 1999, la Corte Constitucional, de manera unánime, decidió conceder -a través de la sentencia SU-600-99 del 18 de agosto de 1999- la acción de tutela por violación al debido proceso y denegación de justicia por parte del Centro.

En su decisión la Corte sentó el principio de que toda autoridad que profiere una decisión tiene la competencia para revisarla, en virtud de la posibilidad que tienen las partes de presentar un recurso de reposición. Igualmente se ocupó de señalar que las decisiones inhibitorias -como las adoptadas por el Centroque carezcan de fundamentos jurídicos válidos, constituyen procedimientos anómalos y censurables, sobre todo cuando dicha decisión se produce en el curso de un procedimiento que busca que la controversia que se encuentra de por medio se resuelva debidamente.

Teniendo como base las anteriores consideraciones, la Corte posteriormente resaltó la importancia que reviste la etapa previa a la iniciación del arbitraje en la que "la garantía del debido proceso y el derecho de defensa pueden resultar comprometidos cuando se violan los preceptos legales que la gobiernan", independientemente de si en dicha etapa se ejercen o no facultades jurisdiccionales (debate éste que la Corte obvió por considerarlo innecesario ante la evidencia de los derechos fundamentales violados por el Centro a las Compañías Merck), aunque la Corte sí dejo en claro que en todo caso al director del Centro le corresponden ejercer atribuciones y poderes procesales "que traslucen una clara 
e indubitable función pública como lo son las diligencias de notificación, admisión y rechazo de la solicitud de convocatoria, decisión de los recursos de reposición, conducción de la audiencia de conciliación, etc.".

La Corte estimó que, si bien los centros de arbitraje no están obligados a resolver todas las peticiones contenidas en un recurso, cuando menos tienen que establecer si, en la cláusula arbitral que se les pone de presente, se menciona a ese centro como el acordado por las partes. Rehusarse a realizar el debido examen de la cláusula compromisoria implica para dichos centros, según la Corte, "correr el riesgo de afincar su competencia sobre bases deleznables".

La Corte aclaró que una cosa es la competencia jurisdiccional del tribunal arbitral y otra la competencia de los centros para efectos de tramitar las solicitudes de convocatoria, adelantar trámites preparatorios y servir de apoyo en la función arbitral. $Y$ es precisamente para propósitos de adelantar estas tareas es que a los centros se les demanda el examen de la cláusula arbitral, independientemente de las labores posteriores que desarrolle el respectivo tribunal. Por eso la Corte advirtió:

"Si bien el Tribunal de Arbitramento, al resolver sobre su propia competencia y establecer si puede entrar a conocer de la controversia arbitral, puede corregir los errores en que eventualmente haya incurrido el Centro al admitir una solicitud de convocatoria dirigida a otra institución -sobre todo cuando se proyecta sobre la selección de la sede y la modalidad interna o internacional del arbitramento-, ello no justifica la ausencia de pronunciamiento inicial por parte del Centro de arbitraje.

"La regulación procesal de la etapa prearbitral le atribuye suficientes facultades al director del centro de arbitraje con el objeto de que pueda tomar la decisión sobre su propia competencia como centro de arbitraje, la cual no se puede confundir con la jurisdicción o competencia del Tribunal de Arbitramento llamado a decidir la controversia. Si no cuenta con este poder jurídico, el 
centro de arbitraje no puede legítimamente conducir la etapa prearbitral.

"El examen jurídico que necesariamente ha de realizar el centro para fijar su competencia como institución arbitral, debe ser suficientemente riguroso y diligente como para permitirle afirmar de manera fundada que aquél corresponde al centro de arbitraje acordado y que concurren, de otro lado, los elementos formales indispensables para impulsar la etapa prearbitral. No es admisible sostener que el centro se encuentre impedido para efectuar este escrutinio de su competencia. Hacerlo obedece a un imperativo jurídico y prudencial, que en modo alguno significa dirimir la controversia ni tiene por objeto resolver sobre la validez de los pactos convenidos".

Con base en estos fundamentos generales la Corte procedió a ocuparse del caso concreto de las Compañías Merck. Para esos efectos, lo primero que cuestionó la Corte fue el silencio - a través de la inhibición- por parte del Centro, pues en la medida en que la cláusula compromisoria defería el conflicto contractual al conocimiento de la Corte Internacional de Arbitraje de la Cámara de Comercio Internacional, bajo un procedimiento y una normativa particular, lo menos a que tenían derecho las Compañías Merck era que se motivara debidamente la decisión del Centro de adelantar la convocatoria arbitral por parte de Tecnoquímicas. En efecto, para la Corte:

"Planteada la cuestión en estos términos, la prosecución del trámite contradice aún el comportamiento inhibitorio seguido, puesto que ella manifiesta una convicción sobre su propia competencia, aunque se opta por no hacer explícitas las razones que le sirven de asidero. La persistencia del Centro en adelantar el trámite prearbitral, no encaja con la inhibición que formula y, por consiguiente, esa ambivalencia que se resuelve contra el recurrente demuestra que la decisión no fue motivada en derecho.

"Por el contrario, la actuación trasluce una dosis alta de voluntarismo amparada en la absoluta reserva sobre las propias razones de ese proceder, lo que no se espera de un particular que cum- 
ple una función pública gobernada por el derecho y que no puede con esa facilidad escamotear la definición de los recursos que son medios de defensa y que por ello exigen una contestación debidamente fundamentada en las normas".

Es por lo anterior que la Corte se cuestiona además en qué norma contractual o legal el Centro basó su propia competencia para adelantar el trámite prearbitral que se cuestiona. A tal punto llega el cuestionamiento, que para la Corte la actuación del Centro no tuvo fundamento distinto que el de una lectura propia de la cláusula compromisoria en que asuntos de tanta relevancia como las reglas de la $\mathrm{CCI}$, la designación de Newark para adelantar el arbitramento y la determinación que el mismo debía surtirse en inglés, fueron obviados. Supone la Corte entonces que el Centro debió haber leído así la cláusula pactada por las partes:

"Todos Ios conflictos relacionados con el presente contrato o con su terminación así como cualquier contrato de ventas aquí mencionado deberá ser solucionado, (...) por uno o más árbitros (...) Cualquier decisión adoptada dentro de dicho procedimiento será definitiva y tendrá efectos de cosa juzgada para ambas partes. Cualquiera de las partes podrá presentar el laudo ante cualquier corte competente para juzgar dicho laudo y hacerlo cumplir. Las partes acuerdan de manera específica dicho procedimiento arbitral, y dicho laudo, así como comparecer ante cualquier corte competente para que este sea juzgado y aplicado por dicha corte".

De lo anterior entiende la Corte que cualquiera que hubiese sido la regla contractual entendida y aplicada por el Centro, lo cierto es que dicha entidad se negó a fundamentar las razones de su decisión, incluso cuando las Compañías Merck le ofrecieron la oportunidad para hacerlo a través del recurso de reposición. Para la Corte, ese silencio por parte del Centro constituyó un "comportamiento que menoscaba arbitrariamente el derecho al debido proceso de la parte interesada". 
Las razones precedentes llevaron pues a la Corte a estimar que los derechos fundamentales al debido proceso y a una debida justicia de las Compañías Merck fueron abiertamente desconocidos por la actuación del Centro. Por ello, advirtió, que "el vicio en que se ha incurrido con la inhibición incide sobre toda la actuación cumplida a partir de la denegación de justicia que se ha producido dentro de esta fase del procedimiento". Y en cuanto a la supuesta y argumentada existencia de otro medio de defensa judicial (como era el caso de las excepciones previas) por parte del Centro y Tecnoquímicas, la Corte señaló que en "estricto rigor, la resolución del Tribunal de Arbitramento, que se cumple de oficio en la primera audiencia de trámite, no tiene el carácter de medio de defensa, sobre todo cuando lo que se cuestiona tiene su raíz en la competencia especifica del Centro de arbitraje para impulsar el trámite prearbitral".

Así las cosas, la Corte Constitucional, de manera unánime, resolvió revocar la sentencia proferida por la Sala de Casación Civil y Agraria de la Corte Suprema de Justicia del 25 de septiembre de 1998 y, en su lugar, confirmar la sentencia proferida por la sala civil del Tribunal Superior de Bogotá el 24 de agosto de 1998.

Con esta decision se dio un paso importante, es cierto, que definió obligaciones para los directores de los centros de arbitraje y que evitará abusos en el futuro; pero ese paso se dio a través de un mecanismo extraño al arbitraje, al margen del arbitraje mismo y con la intervención de tres instancias judiciales diferentes a lo largo de algo más de un año. La incertidumbre jurídica, la indefinición en las reglas del juego y su consecuencia inmediata, la falta de confianza, enemigas por antonomasia del arbitramento, siguen latentes. 


\section{EL MARCO JURÍdiCO QUE SIRVIÓ A LAS DISTINTAS AUTORIDADES COLOMBIANAS PARA RESOLVER el Caso Merck}

Las decisiones que rodearon el Caso Merck forman, entre todas, un marco jurídico para el arbitraje comercial internacional en Colombia que es bastante diferente de lo que se encuentra en los tratados internacionales suscritos por el país sobre la materia e, inclusive, de lo que dispone la ley colombiana. A continuación se analizan las reglas jurídicas más importantes que se derivan de las decisiones que se han descrito a lo largo del presente artículo.

\subsection{La relación entre el conflicto de jurisdicciones y el conflicto de leyes}

Uno de los temas que más ha costado a los jueces dilucidar en Colombia es aquel que tiene que ver con la jurisdicción y ley aplicables a los contratos internacionales. No solamente existe gran incertidumbre en torno al análisis del conflicto de jurisdicciones y al que corresponde al conflicto de leyes, sino que la relación entre uno y otro no se ha establecido de manera clara por los operadores jurídicos del país. La ausencia de un verdadero estatuto de derecho internacional privado ha contribuido sin duda al problema ${ }^{11}$.

Dentro de la disciplina del derecho internacional privado, el análisis del conflicto de jurisdicciones y el de conflicto de leyes son ejercicios separados y autónomos. El primero de ellos, que consiste en determinar cuál es el juez que tiene jurisdicción (y competencia) para decidir un asunto, se realiza con base en normas internas de carácter Constitucional y otras de rango legal y naturaleza procesal. El análisis es siempre unilateral, es decir, los

11. Existencia de un estanto anticuado y unilateral en los arts. 19 y 21 del Código Civil y 869 del Código de Comercio.

268 Revista Ecuatoriana de ARBitraje 
jueces se pronuncian sobre su propia jurisdicción y no sobre la de jueces extranjeros.

Una vez establecida la jurisdicción por el juez, éste aplica sus propias reglas de conflicto para establecer cuál es la ley sustantiva aplicable al fondo de la controversia ${ }^{12}$. En este caso el análisis es bilateral, es decir, la conclusión del juez puede ser que debe aplicar la ley sustantiva del foro o, si su regla de conflicto así lo señala, la de un foro extranjero.

Resulta discutible, por lo menos en sistemas procesales de raigambre europea continental, que sea la ley aplicable al contrato la que determina la jurisdicción de quien debe resolver la controversia. Ninguna disposición en Colombia señala que solamente los jueces colombianos puedan resolver controversias en las que el legislador colombiano señale como aplicable la ley sustantiva del país.

En este caso particular el Tribunal de Arbitraje Colombiano, tal como se describió en el número 1.2 arriba, quiso establecer su jurisdicción a partir de una norma referente a la ley aplicable al caso.

Si tenemos en cuenta el breve análisis que se acaba de hacer sobre la relación entre jurisdicción competente y ley aplicable en el marco del derecho internacional privado, el razonamiento del Tribunal de Arbitraje Colombiano resulta por completo ajeno a derecho. Aun en el supuesto de que los Contratos se denominaran contratos de agencia mercantil y que las partes aceptaran que a ellos se les debía aplicar la ley colombiana, de ello no se sigue que la solución de la controversia sea de conocimiento exclusivo de los jueces colombianos y, menos, de los tribunales de arbitraje con sede en Colombia.

12. Loussouam, Yovon, Bourel, Pierre y đe Vareiles-Sonumières, Pascal. Dooit International privế. 8ème edition. Dalloz, Paris, 2004. p. 12. 
De acuerdo con lo anterior, uno de los legados del Caso Merck es una situación ambigua e incierta sobre cuál es la relación entre el conflicto de jurisdicciones y el conflicto de leyes. El derecho internacional privado indica que se trata de disciplinas separadas y autónomas, y que el primero precede al segundo. En este caso, sin embargo, se estableció la jurisdicción de un tribunal a partir de una norma relativa a la ley aplicable al contrato, y ello bajo el argumento de que cuando la norma se refirió a la ley colombiana, no distinguió entre la ley sustancial y la ley procesal. Desde luego, tratándose de disciplinas separadas, no tenía que hacerlo. Una regla sobre conflicto de leyes no debe confundirse con una regla atributiva de jurisdicción. Por otra parte, aun si se entendiera que la expresión "ley colombiana" incluye la ley procesal, en parte alguna dispone la ley procesal colombiana que la competencia para decidir casos relativos a la agencia mercantil sea exclusiva de los jueces colombianos.

Finalmente debemos señalar que este análisis es ajeno a un escenario arbitral. Como se explicará más adelante, el principio del derecho internacional privado según el cual cada juez establece su jurisdicción y competencia de acuerdo con su propia ley $y$, luego, aplica su propia regla de conflicto, es reemplazado en el arbitraje por aquel según el cual el tribunal de arbitraje designado por las partes es quien debe resolver sobre su propia competencia (kompetenz-kompetenz) con fundamento en el pacto arbitral y establecer, de acuerdo con las normas que resulten aplicables, cuál es la ley sustantiva a la luz de la cual se debe resolver la controversia.

\subsection{La fuente de la competencia de los árbitros}

El Caso Merck tuvo un ingrediente adicional que lo hace atípico dentro del arbitraje. El Tribunal de Arbitraje Colombiano no solamente tomó una decisión a partir de una supuesta ineficacia parcial de las cláusulas arbitrales, sino que basó la ineficacia en el tipo de controversia que era planteada por

270 Revista Ecuatoriana de Arbitraje 
Tecnoquímicas, y en supuestos defectos de los pactos arbitrales. Al tratar de señalar que, por tratarse de una controversia relativa a la existencia de un contrato de agencia mercantil ésta debía ser resuelta por un tribunal de arbitramento con sede en Colombia, el Tribunal de Arbitraje Colombiano dijo, ni más ni menos, que su competencia no derivaba de las Cláusulas Arbitrales, sino de las pretensiones de la demanda.

Esta postura es atípica por varias razones. En primer lugar, se aparta del principio según el cual un tribunal de arbitraje no tiene más competencia que aquella que lícitamente le otorguen las partes en el pacto arbitral. En segundo lugar, so pretexto de preservar la voluntad de las partes de someter sus diferencias a arbitraje, al Tribunal de Arbitraje Colombiano deja sin efecto todo el acuerdo de las partes, salvo la voluntad de someterse a arbitraje, y "crea" un nuevo pacto arbitral totalmente extraño al querer de las partes expresado en el acuerdo original de arbitraje. En tercer lugar, para efectos de asumir competencia califica la relación jurídica subyacente como agencia comercial -aunque intenta argumentar que no hay tal calificación-con lo cual plantea un dilema obvio. Si el Tribunal Colombiano es competente, tiene jurisdicción porque se pide la declaratoria de una agencia mercantil, ¿qué sucede si se concluye al final del debate probatorio que no hay agencia? ¿Revive entonces el pacto original de arbitraje y el Tribunal de Arbitraje Colombiano pierde competencia? En cuarto lugar, si los pactos arbitrales carecían de validez, según el raciocinio del Tribunal de Arbitraje Colombiano, tendría entonces que haberse remitido el caso al juez ordinario que tuviere jurisdicción para conocer del mismo - el juez colombiano según el raciocinio del Tribunal de Arbitraje Colombianoy no a un tribunal arbitral surgido de una interpretación que desconocía de manera casi grosera el querer de las partes pactado en los acuerdos de arbitraje.

Por último, la decisión del Tribunal de Arbitraje Colombiano implicaba una ampliación del ámbito de aplicación del artículo 1328 del Código de Comercio. Pese a que la citada 
norma se refiere al derecho sustancial aplicable al fondo de la controversia, el Tribunal de Arbitraje Colombiano extiende su alcance y señala que la referencia a la ley colombiana del artículo 1328 estado incluye tanto la ley sustantiva como la procesal. De allí concluye que solo al juez colombiano puede pronunciarse sobre conflictos relativos a agencia mercantil que se ejecutan en Colombia y que, en el caso particular de los Contratos, por existir pacto arbitral, solamente un tribunal arbitral colombiano puede resolver la controversia.

\subsection{Las funciones de los centros de arbitraje y la etapa prearbitral}

Es necesario anotar que bajo la ley colombiana en la época del Caso Merck, los centros de arbitraje administraban la etapa prearbitral de la siguiente manera ${ }^{13}$ :(i) admitían la convocatoria; (ii) notificaban a la parte demandada que tenía un determinado plazo para contestar; (iii) atendían una audiencia de conciliación entre las partes; (iv) administraban el nombramiento de los árbitros, ya fuera realizado de común acuerdo por las partes o por el centro mismo, según su reglamento; y (v) entregaban el expediente a los árbitros, para que éstos instalaran el tribunal, se pronunciaran sobre su competencia y, si era el caso, adelantaran el procedimiento arbitral hasta su finalización. En la ley colombiana, no era claro si dichas facultades eran de naturaleza administrativa o judicial. En el Caso Merck, como se vio, este debate adquirió gran importancia ${ }^{14}$.

13. Articulo 121 de la ley 446 de 1998.

14. Al resolver la acción de tutela interpuesta por las Compañias Merck, la Corte Constitucional sostuvo lo siguiente, en relación con la naturaleza de las funciones que ejerce un centro de arbitraje:

"Atin si se aceptare, en gracia de discusión, que el director de un Centro de arbitraje no estuviere revestido de poder jurisdiccional alguno, el ejercicio de la función pública encomendada a él, unido a la circunstancia de que seguin la ley es el competente para decidir los recursos de reposición dirigidos contra sus propios actos, por si sola obligaria a que se resolviera de fondo esta suerte de peticiones, claro estd, descontando que se hubiere dado cumplimiento a los requisitos de ley (I) y, siempre que, para resolverlos, no se requiniera exceder el ámbito de su propia competencia (2).15"

272 Revista Ecuatorlana de ARBitraje 


\subsection{La tutela y el arbitraje}

Uno de los efectos más notorios que tuvo el Caso Merck en relación con el arbitraje en Colombia fue el de abrir la puerta para la utilización de la acción de tutela como un instrumento para intervenir en los procesos arbitrales. Este es un mecanismo constitucional que se utiliza en ausencia de otro medio efectivo de defensa judicial para proteger los derechos fundamentales de las personas, sean ellas naturales o jurídicas.

En el Caso Merck la acción de tutela no se interpuso contra la actuación del tribunal de arbitramento como tal, sino contra el centro de arbitraje. Tampoco se utilizó en busca de que el juez de tutela adoptara una medida de fondo en relación con el proceso arbitral sino, únicamente, para obligar a que un centro de arbitraje adoptara, según su propio criterio sustantivo, una decisión que se negaba a tomar. Más adelante se verá cómo la acción de tutela ha incursionado en el arbitraje en Colombia un alcance mucho mayor, hasta el punto de haberse convertido en un mecanismo alternativo de impugnación del laudo arbitral.

\footnotetext{
"La hipótesis normal, cuando quiera que en un procedimiento establecido por la ley - asi en este caso la actuación se refiera a la etapa prearbitral -, se contempla el recurso de reposición contra un determinado acto dictado por la autoridad que lo conduce, no es la de que esta ultima no disponga de poder juridico suficiente para examinarlo de nuevo y, a la liz de los argumentos de hecho y de derecho expuestos, proceda a ratificarlo, reformarlo, revocarlo, modificarlo, aclararlo o adicionarlo. Seria en verdad contradictorio consagrar el recurso, pero recortar el poder de la autoridad para resolverlo. puesto que su finalidad se encamina a que se pongan de relieve los errores cometidos y que estos puedan ser corregidos. Este objetivo depurador de todo recurso presupone que el autor del acto contra el que se eleva la petición de reposición, tenga plena capacidad para enderezar la actuación. No es concebible que un ordenamiento que busque preservar la validez de los actos que emanan de sus órganos, a la vez que ofrece oportunidades para soltcitar el remedio a la ilegalidad, reduzca a las autoridades las posibilidades efectivas de ordenar el restablecimiento del derecho objetivo conculcado."
}

Los argumentos expuestos sirvieron de base para resolver el caso y ordenar al Centro de arbitraje y Conciliación de la Cámara de Comercio de Bogotá que resolviera el recurso de reposición interpuesto por las Compañias Merck. Quedaba todavía cubierto por un manto de incertidumbre el debate sobre la naturaleza de las funciones que ejerclan los centros de arbitraje durante la etapa prearbitral. 


\subsection{El derecho aplicable al reconocimiento de laudos arbitrales}

Colombia aprobó la "Convención sobre el Reconocimiento y Ejecución de las Sentencias Arbitrales Extranjeras", adoptada por la Conferencia de las Naciones Unidas sobre el Arbitramento Comercial el 10 de junio de 1958 (la "Convención de Nueva York") mediante la ley 37 de 1979. Luego de que ésta fuera declarada inconstitucional por vicios de forma en el trámite de la ley aprobatoria $^{15}$, se expidió la ley 39 de 1990 en su reemplazo. La Corte Suprema de Justicia, juez responsable del reconocimiento de los laudos extranjeros en el país, fijó en 1994 la que sería su posición frente a la aplicación de la Convención de Nueva York. En efecto, decidió una solicitud de exequátur de un laudo extranjero, revisó las causales de denegación de reconocimiento previstas en la Convención de Nueva York, pero también revisó las establecidas en el Código de Procedimiento Civil y estimó que unas y otras aplicaban de manera acumulativa. En la medida que el laudo fue reconocido, la controversia que siguió al fallo fue breve.

En 1996 se expidió la Ley de Arbitraje Internacional y en ella se estableció claramente la prelación de los tratados internacionales sobre el Código de Procedimiento Civil ${ }^{16}$. Esta disposición, unida a una simple aplicación de principios referentes a la aplicación de la ley en el tiempo o a una interpretación básica de los efectos de las convenciones internacionales, ha debido dejar claro que las causales para denegar el reconocimiento de un laudo arbitral extranjero en Colombia son únicamente aquellas previstas en los tratados internacionales suscritos por Colombia y, en este caso, la Convención de Nueva York. Ello se desprende de lo dispuesto en el artículo $\mathrm{V}$ de la misma ${ }^{17}$. Sin embargo, en

15. Corte Suprema de Justicia, sentencia del 6 de octubre de 1988, Sala Plena.

16. Ley 315 de 1996. "Articulo $2^{\circ}$. Normativa aplicable al arbitraje internacional. El arbitraje internacional se regirá en todas sus partes de acuerdo con las normas de la presente ley, en particular por las disposiciones de los Tratados. Convenciones. Protocolo y demás actos de Derecho Internacional suscrilos 1 ratificados por Colombia los cuales priman sobre las reglas que sobre el particular se establecen en el Código de Procedimiento Civil. (...)" (subrayas fuera del texto original).

17. Artículo V de la Convención de Nueva York: "I. Sólo se podrá denegar el reconocimiento y la ejecución de la sentencia, a instancia de la parte contra la cual es invocada, si esta parte prueba ante la autoridad competente del país en que se pide el reconocimiento y la ejecución:" (...) (subrayas fuera de texto original).

274 Revista ECuAtoriana de Arbitraje 
el caso Merck la Corte Suprema de Justicia mantuvo su tesis de la acumulación de causales, añadiendo a las del artículo $\mathrm{V}$ de la Convención de Nueva York las previstas en el artículo $694^{18}$ del Código de Procedimiento Civil, llegando a él por la remisión que hace el artículo 695, numeral 2, del mismo código, norma que se refiere al trámite del exequátur ${ }^{19}$.

Por esta vía la Corte consideró que existen tres circunstancias que impiden el reconocimiento de un laudo extranjero en Colombia que son adicionales a las previstas en la Convención de Nueva York (las previstas en los numerales 1.3 y 4 del Código de Procedimiento Civil), sin tener en cuenta que ésta última exige que se apliquen únicamente las allí previstas y que la Ley de Arbitraje Internacional establece la prevalencia de la

18. "Artículo 694.- Requisitos. Para que la sentencia o el laudo extranjero surta efectos en el país, deberá reunitr los siguienles requisitos:

1. Que no verse sobre derechos reales constituidos en bienes que se encontraban en tcrritorio colombiano en el momento de iniciarse el proceso en que la sentencia se profirió.

2. Que no se oponga a leyes u otras disposiciones colombianas de orden público, exceptuadas las de procedimicnto.

3. Que se encuentre cjecutoriada de conformidad con la ley del país de origen, y se presente en copia debidamente autenticada y legalizada.

4. Que el asunto sobre el cual recae, no sea de competencia exclusiva de los jueces colombianos.

5. Que en Colombia no exista proceso en curso ni sentencia ejecutoriada de jueces nacionales sobre el mismo asunto.

6. Que si se hubiere dictado en proceso contencioso, se haya cumplido el requisito de la debida citación y contradicción del demandado, conforme a la ley del pais de origen, lo que se presume por la ejecutoria.

7. Que se cumpla el requisito del exequátur."

19. "Artículo 695.- Trámite del exequátur. La demanda sobre exequátur de una sentencia o laudo extranjero, con el fin de que produzca efectos en Colombia, se presentará por el interesado a la sala de casación civil de la Corte Suprema de Justicia, salvo que conforme a los tratados internacionales corresponda a otro juez, y ante ella deberd citarse a la parte afectada por la sentencia o el laudo, si hubiere sido dictado en proceso contencioso.

Cuando la sentencia o el laudo no esté en castellano, se presentará con la copia del original su traducción en legal forma.

Para el exequátur se tendrán en cuenta las siguientes reglas:

1. En la demanda deberán pedirse las pruebas que se consideren pertinentes.

2. La corte rechazará la demanda si faltare alguno de los requisitos exigidos en los numerales 1, a 4. del artículo precedente; si advierte deficiencia en la prueba de la existencia o de la representación del demandante o de la persona que en aquélla se cita, dará aplicación a lo dispuesto en el inciso final de articulo $85 .(\ldots)$ 
Convención de Nueva York sobre el Código de Procedimiento Civil.

\subsection{El papel de la sede del arbitraje}

Para la fecha en que se resolvió el Caso Merck, el papel de la sede del arbitraje no había sido estudiado por las autoridades judiciales colombianas. En este caso particular la Corte Suprema de Justicia debió definir la ley aplicable para determinar la naturaleza de una decisión tomada por un árbitro, en un arbitraje con sede en Newark, Nueva Jersey, decisión que el árbitro denominó "interim award" y que fue presentada ante la Corte como un laudo parcial. Ninguna consideración tuvo la Corte por el literal "d)" del numeral $1^{\circ}$, del artículo $\mathrm{V}$ de la Convención de Nueva York, el cual establece como causal de denegación del reconocimiento del laudo arbitral, el que el procedimiento arbitral no se haya llevado a cabo de acuerdo con el acuerdo de las partes al respecto o, en su defecto, de acuerdo con la ley del país donde se ha efectuado el arbitraje. Al tratarse de una circunstancia de naturaleza procesal, la naturaleza del laudo parcial debió establecerse a partir de las normas pactadas por las partes (en este caso el reglamento de la CCI) o, en su defecto, de la lex arbitri y no del "espíritu" de la Convención de Nueva York o del texto de la ley colombiana.

La Corte Suprema de Justicia rechazó este argumento, diciendo que la autoridad de una sentencia arbitral extranjera no es un asunto procesal que deba resolverse a la luz de la ley de la sede del arbitraje $e^{20}$. Para llegar a esta conclusión consideró que el artículo V de la Convención de Nueva York no era la norma dentro de ese instrumento internacional que establecía cuáles eran las providencias que podían, o no, ser objeto de reconocimiento y ejecución en un estado distinto. No especificó, sin

20. Corte Suprema de Justicia, Sala de casación Civil y Agraria. Decisión del primero ( $\left(1^{0}\right)$ de marzo de mil novecientos noventa y nueve (1999). Expediente E-7474. Magistrado ponente, Dr. José Fernando Ramírez Gómez. 
embargo, seguramente porque no lo consideró necesario para resolver el asunto, cuál era el papel que la sede del arbitraje debía jugar en el arbitraje internacional.

\subsection{Los laudos parciales}

En materia de laudos parciales el presente artículo ha descrito en forma detallada cuál es el marco jurídico que sirvió para resolver el caso de Merck. La Corte Suprema de Justicia determinó que la naturaleza de las decisiones dictadas por tribunales arbitrales extranjeros cuyo reconocimiento y ejecución puede solicitarse en Colombia debe establecerse a la luz del "espíritu" de la Convención de Nueva York y de lo dispuesto en la ley colombiana. De acuerdo con la Corte, estos criterios indican que solamente los laudos definitivos, es decir, los que resuelven en el fondo la totalidad de la controversia, pueden ostentar el carácter de sentencias arbitrales extranjeras para efectos de ser reconocidas y ejecutadas en el país.

\subsection{El arbitraje internacional en los contratos de agencia mercantil}

El Tribunal de Arbitramento, al tener por ineficaz la parte de las Cláusulas Arbitrales que establecía la sede del mismo, concluyó que solamente tribunales cuya sede estuviera en Colombia podían resolver sobre cuestiones relativas al contrato de agencia mercantil. Esta conclusión se derivó, como se explicó anteriormente, de la aplicación del artículo 1328 del Código de Comercio, el cual establece que todo contrato de agencia mercantil se rige por la ley colombiana.

Como se advirtió antes, en el Caso Merck los contratos no se denominaron ni, por lo menos en opinión de Merck, eran de agencia mercantil. Este era precisamente el objeto de la controversia. Cabe preguntarse, entonces, si el alcance de la decisión 
del Tribunal de Arbitraje Colombiano se limita a los contratos de agencia mercantil, o si incluye cualquier controversia sobre si un contrato es o no de agencia mercantil, independientemente del resultado de la controversia.

\subsection{Lis pendens y el arbitraje internacional}

Uno de los pronunciamientos más complejos hechos a raíz del Caso Merck pasó relativamente desapercibido cuando el asunto finalmente se resolvió. Este tiene que ver con la litispendencia internacional y el arbitraje comercial. La Corte Suprema de Justicia, en su primer pronunciamiento sobre la posibilidad de reconocimiento del laudo parcial sobre competencia en Colombia, sostuvo lo siguiente:

\footnotetext{
"En efecto, si las partes que supuestamente han convenido resolver su diferencia mediante arbitramento en el extranjero, difieren en su procedencia, en cuanto unos insisten en que debe ser el Tribunal de Arbitramento extranjero el competente, y otros en que debe serlo la jurisdicción colombiana, promoviendo ambos procesos en el exterior y en Colombia, lo pertinente es que dichos aspectos de competencia sean alegados por los demandados separadamente en cada uno de ellos con los riesgos pertinentes. Porque, en tal evento, a la parte demandada en el extranjero e interesada en su adelantamiento en Colombia le corresponde aducir en el proceso arbitral promovido en el extranjero, lo concerniente a la competencia privativa de la jurisdicción colombiana para conocer del asunto, en tanto que a la otra parte interesada en que el adelantamiento del proceso sea en el extranjero le correspondería alegar en el proceso colombiano la excepción correspondiente de cláusula compromisoria o arbitral, a fin de que la decisión, positiva o negativa, que tome el juez colombiano sea la que prevalezca, sin pexjuicio, desde luego, de los recursos ordinarios o extraordinarios y medios de defensa que, de acuerdo al orden jurídico colombiano, existan contra ella. En todo caso dicha prevalencia obedece al carácter de orden público e impera-
} 
tivo de las normas procesales, y al principio general de la territorialidad de estas últimas. De esta manera entonces debe resolverse la situación de competencia que eventualmente pueda plantearse, porque será la decisión en materia de competencia que profiera el juez colombiano la que prevalezca, sin que para ello sea preciso la intervención de un exequátur en dicho punto." (Subrayado fuera del texto original).

El pronunciamiento trascrito pareciera redactado para un evento de litispendencia internacional entre dos jueces estatales. Sin embargo, se hizo a raíz de un caso arbitral, lo cual complica seriamente el asunto. Ya se ha dicho a lo largo del presente artículo que, según los principios y reglas que gobiernan el arbitraje comercial internacional en Colombia y en las convenciones internacionales, es el tribunal previsto en la cláusula arbitral eI que debe pronunciarse sobre su propia competencia (y no, como ocurrí en el Caso Merck, un tribunal arbitral diferente) y esta decisión debe ser respetada por los jueces. Este es el alcance de lo dispuesto en el artículo II, numeral $3^{\circ}$ de la Convención de Nueva York:

“3. El Tribunal de uno de los Estados Contratantes al que se someta un litigio respecto del cual las partes hayan concluido un acuerdo en el sentido del presente artículo, remitirá a las partes al arbitraje, a instancia de una de ellas, a menos que compruebe que dicho acuerdo es nulo, ineficaz o inaplicable."

Establecida prima facie la validez del pacto arbitral por el juez, éste debe remitir a las partes al arbitraje previsto en la cláusula. Esto significa que, salvo que prima facie el juez establezca la nulidad, ineficacia o inaplicabilidad de la cláusula arbitral, debe remitir a las partes al arbitraje previsto en el pacto arbitral.

En el Caso Merck, la Corte Suprema de Justicia argumentó la improcedencia del reconocimiento del laudo parcial no solamente porque en su criterio no era un laudo propiamente dicho, sino porque en materia de litispendencia internacional habría 
que estarse por lo resuelto por el juez colombiano que conozca del proceso respectivo. Esto sería admisible, a nuestro juicio, si se tratara de un caso de litigios paralelos ante jueces estatales ${ }^{21}$. Pero resulta inadmisible aplicar el mismo principio a un caso como este porque, sencillamente, la norma no supone la existencia de procesos arbitrales paralelos, dado que el pacto arbitral es uno solo. En materia de arbitraje el tema de la litispendencia, entendida como la posibilidad de procesos arbitrales paralelos, es inexistente. El tema de fondo en el campo del arbitraje es el de kompetenz-kompetenz, por lo que la prioridad dada por la Corte Suprema de Justicia al juez doméstico en el caso de litispendencia entre jueces estatales, corresponde dársela al tribunal de arbitramento previsto en el pacto arbitral cuando se trata de un conflicto en el marco de un pacto arbitral. La Corte Suprema de Justicia se rehusó a hacerlo y optó por favorecer la decisión de un tribunal de arbitramento constituido en Colombia, en claro desconocimiento de lo dispuesto por el pacto arbitral.

\section{La eVOLUCIÓN DEL arbitraje COMERCIAL INTERNACIONAL COLOMBIANO DESDE MERCK hasta hoY}

El marco jurídico que se desprende del análisis hecho en el punto anterior ha sufrido algunas modificaciones durante la década que ha trascurrido desde el Caso Merck. A continuación se señalarán aquellos campos del arbitraje señalados en el punto anterior que han sufrido cambios a lo largo de los últimos años y se explicará en qué forman han evolucionado hasta hoy.

21. El artículo 694, numeral $5^{\circ}$ del código de procedimiento civil establece que el exequátur de una sentencia extranjera será negado cuando en Colombia exista un proceso sobre ei mismo asunto. 


\subsection{Las funciones de los centros de arbitraje y la etapa prearbitral}

Este tema fue objeto de un nuevo pronunciamiento por parte de la Corte Constitucional colombiana ${ }^{22}$ en el cual se definió la naturaleza jurisdiccional de la llamada etapa prearbitral y se concluyó que las normas respectivas eran contrarias a la Constitución Nacional. Dijo la Corte:

"Conforme a lo anterior, la Corte concluye que la fase prearbitral tiene una naturaleza jurisdiccional, por las siguientes razones: i) puede implicar limitaciones al acceso a la administración de justicia; ii) está destinada a impulsar el proceso arbitral, que es de naturaleza jurisdiccional, y iii) en su fondo y forma está sometida a lo previsto en el estatuto procesal civil para los procesos judiciales."

Con base en la consideración trascrita, la Corte estimó que las funciones asignadas a los centros de arbitraje durante la etapa prearbitral eran de naturaleza judicial y, por lo tanto, debían ser ejercidas por el tribunal arbitral, una vez se hubiera constituido.

Si esta interpretación de la ley hubiera estado vigente al momento de ocurrir el Caso Merck, el Tribunal de Arbitramento Colombiano hubiera logrado mantener su jurisdicción y decidir el caso, generando el problema de litigios arbitrales paralelos que se analizó anteriormente.

Esta es hoy la situación del derecho colombiano en materia de facultades de los centros de arbitraje. La Corte Constitucional determinó que son los árbitros quienes deben pronunciarse sobre la procedencia de la demanda, lo que indirectamente implica que son ellos quienes se pronuncian, además, sobre la admisibilidad prima facie del pacto arbitral, quitando esta posibilidad a los centros de arbitraje.

22. Corte Constitucional. Sentencia C-1038-02 del 28 de noviembre de 2002. Magistrado ponente: Dr. Eduardo Montealegre Lynett. 


\subsection{La tutela y el arbitraje}

El Caso Merck fue uno de los pioneros en materia de utilización de la acción de tutela en torno a procesos arbitrales. Desde entonces la acción de tutela ha jugado un papel cada vez más activo en el campo del arbitraje, hasta el punto de que hoy existe una doctrina Constitucional sobre procedencia de la acción de tutela contra laudos arbitrales. Esta doctrina, en síntesis, dispone que la acción de tutela proceda contra laudos arbitrales en uno de cuatro eventos ${ }^{23}$ :

(i) Vía de hecho por defecto sustantivo, la cual se configura cuando se utiliza un poder concedido al juez por el ordenamiento para un fin no previsto en la disposición, cuando la decisión se encuentre fundada en una norma claramente inaplicable al caso concreto, o cuando la decisión impugnada se funda en una norma evidentemente inaplicable.

(ii) Vía de hecho por defecto orgánico, la cual se presenta cuando se da el ejercicio de la atribución por un órgano que no es su titular, es decir, cuando un funcionario ejerce una competencia que la ley no le asigna.

(iii) Vía de hecho por defecto procedimental, cuando la actuación ocurre por fuera del procedimiento establecido. Se presenta en aquellos casos en los cuales el juez se desvía por completo del procedimiento fijado por la ley para dar trámite al proceso respectivo y conduce a una amenaza o vulneración de los derechos y garantías de alguna de las partes o de los demás sujetos procesales con interés legítimo.

(iv) Vía de hecho por defecto fáctico, la cual se configura mediante la aplicación del derecho sin contar con el

23. Corte Constitucional. Sentencia \$U-0174-07 del catorce (14) de marzo de dos mil siete (2007). Magistrado ponente, Dr. Manuel José Cepeda Espinosa. 
apoyo de los hechos determinantes del supuesto legal, o en otras palabras, cuando "resulte incuestionable que el juez no tiene el apoyo probatorio que permita la aplicación del supuesto legal en el que se sustenta la decisión". Ha explicado la Corte que "los defectos fácticos pueden agruparse en dos clases. La primera, la dimensión omisiva, comprende las omisiones en la valoración de pruebas determinantes para identificar la veracidad de los hechos analizados por el juez. La segunda, la dimensión positiva, abarca la valoración de pruebas igualmente esenciales que el juzgador no puede apreciax, sin desconocer la Constitución".

Las anteriores casuales de procedencia de la tutela contra laudos arbitrales claramente pueden llegar a requerir un estudio de la argumentación utilizada por un tribunal de arbitramento para decidir el fondo del caso. La conclusión a que conduce esta doctrina constitucional es que la acción de tutela en Colombia lo que ha hecho es ampliar las posibilidades de cuestionamiento de laudos arbitrales, en algunos casos permitiendo que el juez constitucional evalúe los argumentos jurídicos que sirvieron de fundamento a la decisión arbitral.

Recientemente ${ }^{24}$ la Corte Constitucional anuló un laudo arbitral en una decisión que confirma que la acción de tutela ha ampliado el campo para cuestionar decisiones arbitrales. Se trataba de un laudo respecto del cual se encontraba en curso el recurso de anulación y, a pesar de ello, la Corte Constitucional decidió conocer del asunto, con el siguiente argumento:

"Entonces, queda claro que en el presente caso el recurso de anulación no es idóneo para obtener la protección constitucional invocada, pues la legislación y la jurisprudencia restringen las facultades del juez que conoce de dicho recurso a la valoración de las causales previstas en las normas que regulan la materia, y a su

24. Corte Constitucional. Sentencia T-058 DE 2009 del dos (2) de febrero de dos mil nueve (2009). Magistrado ponente, Dr. Jaime Araujo Rentería. 
vez, a las alegadas por el interesado. En esta medida dada la naturaleza constitucional de la acción de tutela, ésta constituye el único mecanismo susceptible de ser invocado a fin de garantizar la protección de los derechos fundamentales presuntamente conculcados por el Tribunal de Arbitramento Telefónica Móviles Colombia S.A. Vs. Empresa de Telecomunicaciones de Bogotá S.A. E.S.P." (Subrayado fuera del texto original)

El aparte trascrito es claro en determinar que la acción de tutela es un mecanismo para cuestionar laudos arbitrales que es adicional al recurso de anulación, el cual la Corte encontró excesivamente restringido:

"Es decir, las facultades del juez de la jurisdicción administrativa son muy restringidas si se compara con las facultades del juez constitucional para determinar y decidir sobre la afectación de derechos fundamentales en estos casos."

Con base en este argumento sobre la procedibilidad de la acción de tutela la Corte Constitucional anuló el laudo arbitral, luego de encontrar que el tribunal había interpretado de manera errada las facultades de la Comisión de Regulación de Telecomunicaciones y algunos actos administrativos expedidos por ella. Esta posición de la Corte sugiere que la acción de tutela en el arbitraje en Colombia ha pasado de ser, como lo fue en el Caso Merck, un instrumento para la protección del derecho al debido proceso, a constituir un recurso adicional contra el laudo arbitral.

\subsection{El derecho aplicable al reconocimiento de laudos arbitrales}

Recientemente la Corte Suprema de Justicia tomó una decisión que implicaba adoptar una postura sobre cuáles son las causales que en Colombia pueden dar lugar a la denegación del exequátur de un laudo arbitral extranjero ${ }^{25}$. Admitida la demanda

25. Corte Suprema de Justicia. Sala de Casación Civil. Diecinueve (19) de mayo de dos mil nueve (2009). Expediente 1100102030002008-01760-00. Solicitud de exequátur de Drummond Ltd. Contra la NACIÓN-Ministerio de Transporte- y Ferrocarriles del Norte de Colombia S.A. -FENOCO- 
de exequátur que se interpuso contra un laudo arbitral, la parte demandada recurrió al auto admisorio sobre la base de que la demanda debía rechazarse por no cumplir con los requisitos exigidos por el artículo 695 del Código de Procedimiento Civil. Dos de los requisitos que se consideraban omitidos consistían en que se consideraban violados los numerales $1^{\circ}$ y $2^{\circ}$, del artículo 694 del Código de Procedimiento Civil, a los cuales remite al artículo 695. Estos dos requisitos son los siguientes:

"1. Que no verse (el laudo) sobre derechos reales constituidos en bienes que se encontraban en territorio colombiano en el momento de iniciarse el proceso en que la sentencia se profirió;

y

“2. Que no se oponga (el laudo) a leyes $\mathbf{u}$ otras disposiciones colombianas de orden público, exceptuadas las de procedimiento."

Estos requisitos son ajenos a lo dispuesto en la Convención de Nueva York y, por lo tanto, en cumplimiento del artículo $V$ de la misma, la Corte Suprema de Justicia ha debido señalar que no pueden tenerse en cuenta para efectos de decidir si se concede o no el exequátur. De la misma manera, la Corte ha debido decir que supeditar la admisión de la demanda de exequátur al cumplimiento de esos dos requisitos equivale a exigir su cumplimiento para efectos de conceder el exequátur y, por lo tanto, no procede el estudio de la alegación presentada por la demandada.

La Corte, sin embargo, tomó otro camino. A lo largo de la providencia analizó cada una de las condiciones que el recurrente había considerado violadas y luego concluyó que no existía tal violación. Esta postura reafirma la infortunada tesis de la Corte Suprema de Justicia en el sentido de que las condiciones establecidas en el Código de Procedimiento Civil Colombiano para denegar el exequátur, por lo menos aquellas cuyo cumplimiento aparece como requisito para la admisión de la demanda de exequátur, continúan vigentes. Esto, a pesar de que Colombia 
sea parte de la Convención de Nueva York, cuyo artículo V limita la posibilidad de negar el exequatur a cinco causales que deben ser invocadas a instancia de parte y dos que pueden ser declaradas de oficio por el juez de reconocimiento.

\subsection{El papel de la sede del arbitraje}

Los tribunales colombianos únicamente han tenido oportunidad de pronunciarse sobre el papel de la sede del arbitraje en una ocasión adicional, después del Caso Merck. En el caso de Empresa Colombiana de Vías Férreas -FERROVIAS- vs. Drummond Ltd., el Consejo de Estado admitió un recurso de anulación contra un laudo parcial dictado por un tribunal cuya sede era París, Francia. Drummond Ltd. inició un incidente de nulidad en contra de la actuación que produjo la admisión del recurso de anulación de un laudo proferido por fuera de Colombia, y el Consejo de Estado anuló la actuación, con la siguiente argumentación ${ }^{26}$ :

"Olvida la parte recurrente que la definición de la sede del arbitraje, efectuada por las partes en el pacto, no es un asunto accidental ya que determina, entre otros aspectos, la interacción de las cortes del lugar con el tribunal, en particular, en cuanto a la posibilidad de anulación del laudo arbitral, de acuerdo con las causales y el procedimiento de su legislación. En conclusión, al haberse pactado en la cláusula arbitral que las controversias se someterían a un tribunal organizado según las reglas del Centro de arbitraje y Conciliación de la Cámara de Comercio de París, que esa ciudad fue la sede del arbitraje y que los árbitros señalaron que la lex arbitri sería el derecho francés, el conocimiento del recurso de anulación propuesto en su contra, no es competencia del Consejo de Estado Colombiano".

26. Consejo de Estado. Sala de to contencioso administrativo. Sección tercera. Consejero ponente: Ricardo Hoyos Duque. Bogotá, D.C., veintidós (22) de abril de dos mil cuatro (2004). Radicación número: 11001-03-26-000-2003-00034-01(25261). Actor: EMPRESA COLOMBIANA DE VIAS FÉRREAS-FERROVIAS. 
Este pronunciamiento deja claro que el Consejo de Estado colombiano atribuyó a la sede del arbitraje los efectos que normalmente se asocian con ella. Dijo que el recurso de anulación se sometería a las cortes del lugar de la sede y que serían las cortes de ese país, las que podrían interactuar con el tribunal arbitral. Nada se dijo, porque no era materia de discusión, si la ley de la sede es la que debe determinar la naturaleza de una decisión arbitral para efectos de su reconocimiento en un país extranjero.

\subsection{Los laudos parciales}

La misma decisión discutida en el punto anterior trató, tangencialmente, el tema de los laudos parciales. El laudo contra el cual FERROVIAS interpuso recurso de anulación ante el Consejo de Estado era un laudo parcial. En la medida que la discusión se centró sobre la procedencia del recurso de anulación contra laudos proferidos por tribunales cuya sede queda fuera de Colombia, no se entró a fondo en la discusión sobre la procedencia del recurso de anulación contra un laudo parcial. Sin embargo, el Consejo de Estado alcanzó a afirmar lo siguiente sobre el tema:

"(...) IIII. Por último, la sala advierte que, en el presente caso, el recurso de anulación que se formuló ante esta sección, lo fue contra un laudo arbitral parcial (que el recurrente denominó preliminar), proferido por un tribunal de arbitraje internacional[*] el 24 de junio de 2003, el cual decidió sobre las "cuestiones preliminares" planteadas en la demanda y en la contestación de la misma, esto es, las objeciones formuladas por las partes, la citación de las diferentes empresas demandadas (Ferrovías, Fenoco y Dragados) con ocasión de la cesión de que fue el objeto el contrato operacional de transporte que se celebró con Drummond Ltd., la solicitud de medidas provisionales y el rechazo de la demanda reconvencional introducida por Fenoco.

"Posteriormente, se allegó al expediente copia del laudo final que profirió el mismo tribunal de arbitraje el 15 de julio del mismo año (fls. 815 a 862). 
"Resulta, por tanto, discutible que el laudo parcial cuya nulidad se pide sea impugnable en forma separada, ya que se trata de una providencia que se limitó a impulsar el respectivo trámite y que las decisiones de fondo de la controversia planteada están contenidas en el laudo final." (Subrayas fuera del texto original)

En esta decisión el Consejo de Estado se abstiene de pronunciarse de fondo sobre la procedencia del recurso de anulación en contra de laudos parciales, discusión que es análoga a la que se dio en la Corte Suprema de Justicia en el Caso Merck con ocasión de la solicitud de reconocimiento de los mismos. Si bien se trata de tribunales diferentes y en un caso se trata del recurso de anulación y en el otro del procedimiento para el reconocimiento y posterior ejecución del laudo, la doctrina en Colombia sobre la naturaleza de los laudos parciales debería ser uniforme para los casos de anulación y reconocimiento. El hecho que el Consejo de Estado haya planteado este tema como una duda, en lugar de tomar la doctrina de la Corte Suprema de Justicia en el Caso Merck, permitiría suponer que el alto tribunal está dispuesto a estudiar el tema en un futuro.

La discusión del tema en sede de anulación (por parte del Consejo de Estado o de un Tribunal Superior de Distrito Judicial, que es el juez de anulación en los casos de arbitrajes entre partes privadas) sería similar a la que se dio ante la Corte Suprema de Justicia en sede de reconocimiento, pero tendría un ingrediente que podría hacer que la uniformidad deseable en esta materia no se produjera fácilmente: la lex arbitri, que es la que debería determinar la naturaleza del laudo parcial, es diferente en uno y otro caso. Para efectos del recurso de anulación la lex arbitri es siempre la ley colombiana, pues los recursos de anulación que se tramitan ante los jueces colombianos son exclusivamente aquellos referentes a laudos proferidos por tribunales arbitrales cuya sede es Colombia. En el caso de reconocimiento, debería ser la ley de la sede del tribunal en el extranjero. Este tema continúa pendiente de solución por las autoridades judiciales colombianas y será interesante ver si esta dicotomía de alguna manera les 
impide llegar a la conclusión de que la lex arbitri debe determinar la naturaleza de la decisión y no el "espíritu" de la Convención de Nueva York o la ley colombiana.

\subsection{El arbitraje internacional en los contratos de agencia mercantil}

Una de las preguntas más significativas que surge del Caso Merck es si, en efecto, puede pactarse arbitraje internacional en contratos de agencia mercantil o que pudieran ser clasificados como tales. El Tribunal de Arbitraje Colombiano dio a entender que no, acudiendo al artículo 1328 del Código de Comercio colombiano. Esta interpretación, de haber hecho carrera, habría puesto en peligro la posibilidad de someter a arbitraje las controversias de la mayoría de contratos de intermediación mercantil.

Este tema por si solo, es suficiente para un escrito independiente. Por ahora bastaría decir que hoy día se continúa pactando, de la misma manera que se había hecho en el Caso Merck. Muchos intermediarios que pretenden que se les declare agentes, posiblemente en un intento por evitar las controversias que surgieron en torno al Caso Merck, han decidido presentar sus reclamaciones ante la justicia ordinaria, argumentando la existencia de una agencia comercial de hecho, al margen de la relación contractual que los une con el empresario. En la práctica el arbitraje internacional como tal continúa vigente para los contratos de intermediación mercantil, así ellos sean o corran el riesgo de ser clasificados como contratos de agencia mercantil.

\section{Conclusión}

El Caso Merck fue uno de los primeros casos de arbitraje comercial internacional que perneó el sistema jurídico colombiano en varias de sus instancias. Las decisiones que adoptaron las Corte Suprema de Justicia y la Corte Constitucional de 
Colombia, así como el Tribunal de Arbitraje Colombiano y el Centro de Arbitraje y Conciliación de la Cámara de Comercio de Bogotá han tenido grandes repercusiones en el mapa jurídico del arbitraje comercial internacional en el país.

Hoy, algunas cosas siguen igual y otras han cambiado. Persiste la incertidumbre sobre cuáles son las causales de denegación de un exequátur que aplicará la Corte Suprema de Justicia y si ésta insistirá en que las contenidas en Código de Procedimiento Civil deben acumularse con las que establece la Convención de Nueva York. La acción de tutela se ha convertido en un actor importante en el mundo del arbitraje, hasta el punto que podemos afirmar que los tribunales internacionales cuya sede sea Colombia pueden quedar expuestos a la intervención 0 , inclusive, a la anulación del laudo por parte de un juez de tutela. Los laudos parciales siguen siendo, a la luz de los jueces de anulación y reconocimiento en Colombia, meras órdenes de procedimiento que no pueden reconocerse o anularse. La solución de controversias en los contratos de intermediación mercantil continúa incierta y genera, por lo general, procesos distintos (uno con base en el contrato y otro sobre una supuesta agencia de hecho) sobre una misma relación jurídica. Estos motivos de incertidumbre, muchos de ellos atribuibles a las decisiones que se produjeron en el Caso Merck tomarán, para resolverse, más de la década que ha transcurrido desde entonces.

* Cabe precisar que el laudo recurrido no fue proferido por la Corte Intemacional de Arbitraje de la Cámara de Comercio Internacional (CCI), como se dijo en el auto suplicado. En efecto, dicha Corte no es un "tribunal" en el sentido tradicional del témmino. Su misión es la de asegurar la aplicación del reglamento de arbitraje de la CCI. La Corte no resuelve por si misma las controversias sometidas a arbitraje, función que comesponde a los ártittos nombrados de acuerdo con el Reglamento, sino que supervisa el procedimiento. La Corte nombra los árbitros o confirma aquellos designados por las partes, se pronuncia sobre la admisibilidad o no de la demanda, la recusación de los árbitros, examina y aprueba los laudos arbitrales y fija los honorarios de los árbitros. (Veánse, apéndices I y II del Reglamento de arbitraje de la CCI). 